\title{
PENGEMBANGAN SI STOK BARANG DENGAN PERAMALAN MENGGUNAKAN METODE DOUBLE EXPONENTIAL SMOOTHING (STUDI KASUS : PT. TOMAH JAYA ELEKTRIKAL)
}

\author{
Cahyarizki Adi Utama, Yan Watequlis S. \\ Teknologi Informasi, Teknik Informatika, Politeknik Negeri Malang \\ cahyarizki93@gmail.com
}

\begin{abstract}
Abstrak
PT. Tomah Jaya Elektrikal adalah perusahaan yang bergerak dibidang kontraktor listrik dalam mengelola bisnisnya terdapat 2 bidang pekerjaan yaitu bidang administrasi dan bidang pekerjaan lapangan. Bidang administrasi bertugas mengelola kebutuhan bidang lapangan. Petugas bidang administrasi sering salah dalam stok barang terkadang kebutuhan barang yang dipesan kurang yang mengakibatkan terhentinya pekerjaan dibidang pekerjaan lapangan. Dan apabila ketersediaan barang terlalu banyak mengakibatkan kerugian dalam biaya perawatan bahkan barang mengalami penurunan kualitas dikarenakan terlalu lama tersimpan. Untuk meminimalkan dan mengatasi permasalahan tersebut perlu adanya suatu system terkomputerisasi yang dapat meramalkan kebutuhan stok barang secara optimal. Dan dapat memenuhi kebutuhan barang pada saat pelayanan. Metode yang digunakan adalah Double Exponential Smoothing karena Metode ini tergolong dalam metode time series (runtut waktu) yang mempergunakan data masa lalu untuk memprediksi sesuatu di masa yang akan datang. Data yang akan digunakan juga menunjukkan adanya trend. Sistem ini dapat meramalkan kebutuhan stok barang untuk 1 periode / 1 bulan kedepan agar stok barang optimal. Dalam peramalan menggunakan metode ini nilai alpha $(\alpha)$ sangat berpengaruh terhadap kesalahan / error dari peramalan.
\end{abstract}

Kata kunci : Sistem Informasi, Double Exponential Smoothing, PT. Tomah Jaya Elektrikal

\section{Pendahuluan}

\subsection{Latar Belakang}

PT.Tomah Jaya Elektrikal adalah Perusahaan yang bergerak dibidang kontraktor listrik yang sudah terdaftar dalam AKLI (Asosiasi Kontraktor Listrik dan Mekanikal Indonesia). Di perusahaan ini terdiri dari 2 bidang pekerjaan yaitu bidang administrasi dan bidang pekerjaan lapangan.

Petugas bidang administrasi sering salah dalam stok barang, terkadang kebutuhan barang yang dipesan kurang yang mengakibatkan terhentinya pekerjaan dibidang pekerjaan lapangan. Dan apabila ketersediaan barang terlalu banyak mengakibatkan kerugian dalam biaya perawatan bahkan barang mengalami penurunan kualitas dikarenakan terlalu lama tersimpan. Menjaga agar ketersediaan barang terjamin keberadaannya merupakan tugas seorang petugas administrasi untuk memenuhi kebutuhan bidang pekerjaan lapangan.

Dalam Penelitian ini penulis mengembangkan Sistem Informasi Stok Barang yang dapat meramalkan kebutuhan stok dalam 1 periode/ 1 bulan kedepan menggunakan metode Double Exponential Smoothing agar stok barang optimal.

\subsection{Rumusan Masalah}

a. Bagaimana cara mendapatkan peramalan kebutuhan stok barang agar optimal untuk satu periode kedepan dengan memanfaatkan data barang keluar periode sebelumnya?

b. Bagaimana agar stok barang memenuhi kebutuhan pekerjaan lapangan?

\subsection{Tujuan Penelitian}

a. Membantu memprediksi kebutuhan stok barang untuk satu bulan kedepan agar stok barang optimal.

b. Memenuhi kebutuhan barang bidang pekerjaan lapangan.

\subsection{Batasan Masalah}

a. Sistem Informasi ini memprediksi kebutuhan stok barang untuk kebutuhan barang satu bulan kedepan.

b. Sistem Informasi ini menggunakan metode Double Exponential Smoothing untuk dapat memprediksi stok barang.

c. Kriteria yang digunakan sebagai parameter peramalan yaitu data bulan sebelumnya. 


\section{Landasan Teori}

\subsection{PT.Tomah Jaya Elektrikal}

PT.Tomah Jaya Elektrikal adalah Perusahaan yang bergerak dibidang kontraktor listrik yang sudah terdaftar dalam AKLI (Asosiasi Kontraktor Listrik dan Mekanikal Indonesia). Dan merupakan perusahaan yang mendapatkan tender dari PT.PLN (Persero) UP Dinoyo untuk mengerjakan pekerjaan dibidang penyambungan listrik seperti tambah daya, perubahan daya, dan migrasi.

\subsection{Forecasting (Peramalan)}

Forecasting bertujuan untuk mendapatkan peramalan atau prediksi yang bisa meminimumkan kesalahan dalam meramal yang biasanya diukur dengan mean square error, mean absolute error (Pangestu, 1986).

\subsection{Exponential Smoothing}

Smoothing adalah mengambil rata - rata dari nilai pada beberapa periode untuk menaksir nilai pada suatu periode (Pangestu Subagyo, 1986:7), Exponential Smoothing adalah suatu metode peramalan ratarata bergerak yang melakukan pembobotan menurun secara exponential terhadap nilainilai observasi yang lebih tua (Makridakis, 1993:79)

\subsection{Double Exponential Smoothing}

Metode Double Exponential Smoothing merupakan model linear yang dikemukakan oleh Brown. Dalam metode ini dilakukan proses smoothing dua kali. Dasar pemikiran metode pemulusan eksponensial linear dari Brown adalah serupa dengan rata-rata bergerak linear, karena kedua nilai pemulusan tunggal dan ganda ketinggalan dari data yang sebenarnya jika terdapat unsur trend. Perbedaan antara nilai pemulusan tunggal dan ganda dapat ditambahkan dengan nilai pemulusan tunggal dan disesuaikan untuk trend. Persamaan yang dipakai dalam implementasi pemulusan eksponensial linear satu-parameter dari Brown adalah sbb:

a. Pemulusan Eksponensial Tunggal: $S_{t}^{\prime}=$ $\alpha X_{t}+(1-\alpha) S_{t-1}^{\prime} \ldots . .(1)$

b. Pemulusan Eksponensial Ganda: $S^{\prime \prime}{ }_{t}=$ $\alpha S_{t}^{\prime}+(1-\alpha) S_{t-1}^{\prime \prime}$

c. Dimana $S_{t}^{\prime}$ adalah nilai pemulusan eksponensial tunggal dan $S^{\prime \prime}{ }_{t}$ adalah nilai pemulusan eksponensial ganda

d. Pemulusan Trend:

$$
\begin{aligned}
& \alpha_{t}=S_{t}^{\prime}+\left(S_{t}^{\prime}-S^{\prime \prime}{ }_{t}\right)=2 S^{\prime}{ }_{t}-S^{\prime \prime}{ }_{t}(3) \\
& b_{t}=\frac{\alpha}{1-\alpha}\left(S^{\prime}{ }_{t}-S^{\prime \prime}{ }_{t}\right) \ldots \ldots \ldots \ldots \ldots \ldots \ldots \ldots \ldots \ldots \ldots \ldots \ldots \ldots
\end{aligned}
$$

e. Ramalan

$$
F_{t+m}=a_{t}+b_{t}(m)
$$

Dimana $m$ adalah jumlah periode ke muka yang akan diramalkan.

\subsection{Ukuran ketepatan metode}

Deviasi Absolute Rerata / Mean Absolute Error (MAD)

$$
M A D=\frac{\sum\left|e_{t}\right|}{\mathrm{n}}
$$

Untuk menghitung MAD setiap kesalahan diabsolutekan(tidak diperhatikan tanda positif dan negative) kemudian dibagi dengan banyaknya data.

\section{Metodologi}

\subsection{Metode Pengembangan Sistem}

Metode yang digunakan untuk penelitian ini adalah System Development Life Cycle (SDLC) model waterfall.

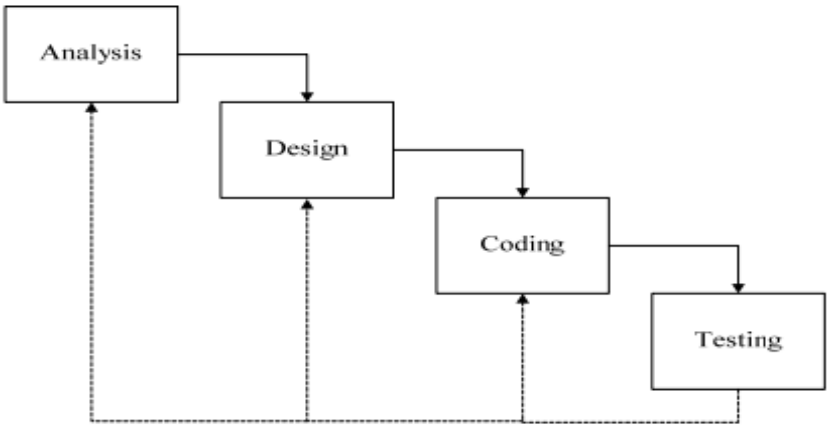

Gambar 3.1 Model Waterfall

\subsection{Pengambilan Data}

\section{a. Studi Literatur}

Pengumpulan informasi dilakukan dengan berbagai sumber berupa buku, paper, jurnal dalam bentuk cetak maupun melalui website. Teori yang dipelajari yaitu peramalan menggunakan metode Double exponential smooting.

\section{b. Wawancara}

Tahapan pengumpulan data ini dilakukan untuk memperoleh data dan informasi yang diperlukan dalam Pengembangan Sistem Informasi Stok Barang dengan Peramalan Menggunakan Metode Double Exponential Smoothing dengan cara wawancara kepada pemilik dan petugas administrasi . Hasil dari wawancara didapatkan data stok barang yaitu data barang keluar dan data barang masuk. Data barang keluar nantinya akan digunakan sebagai acuan peramalan untuk melakukan stok barang pada periode selanjutnya. 


\section{Analisis dan Perancangan}

\subsection{Deskripsi Sistem}

Sistem ini bertujuan untuk Membantu memprediksi kebutuhan stok barang untuk satu bulan kedepan agar stok barang optimal. Dengan mengaplikasikan metode peramalanan yaitu dengan metode Double Exponential Smoothing. Data barang keluar nantinya akan digunakan untuk acuan peramalan stok barang untuk satu bulan kedepan. Sistem ini juga terdapat menu untuk mengelola data barang keluar dan data barang masuk

\subsection{Desain Sistem}

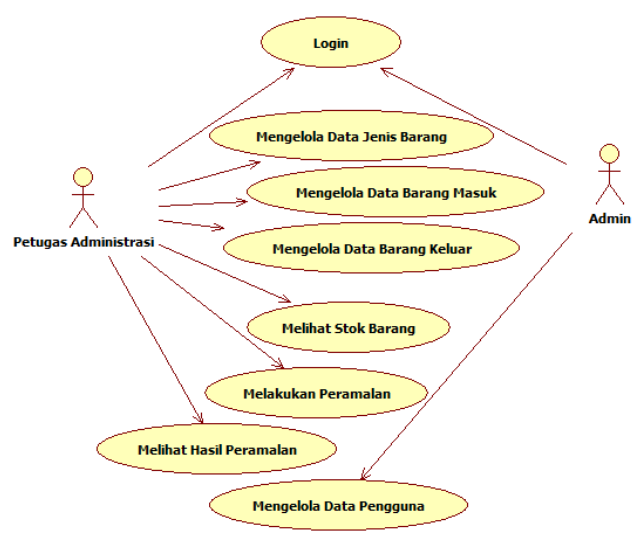

Gambar 4.2 Use Case Diagram

\subsection{Desain Database}

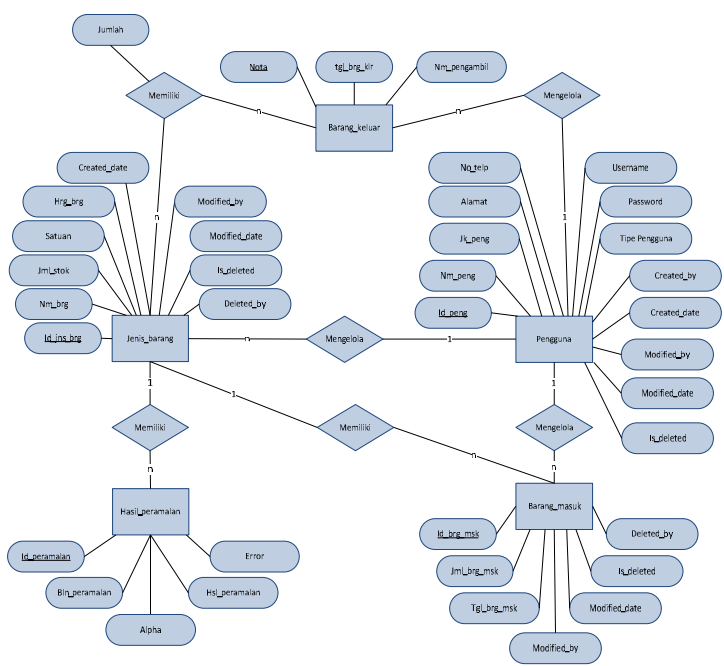

Gambar 4.3 ERD

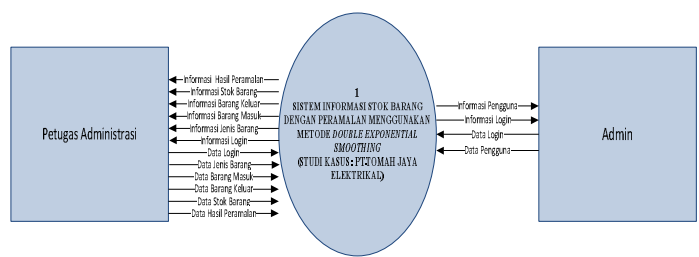

Gambar 4.4 Context Diagram

\section{Implementasi}

\subsection{Implementasi Database}

- 3 si_stokbrg

† Database Diagrams

$\square$ Tables

† System Tables

†. dbo.Barang_keluar

Ð

†国 dbo.Detail_barang_keluar

Ð

†.

\pm 国 dbo.Kode

†

Gambar 5.1 Struktur Database

\subsection{Implementas Sistem}

\section{a. Halaman Menu Login}

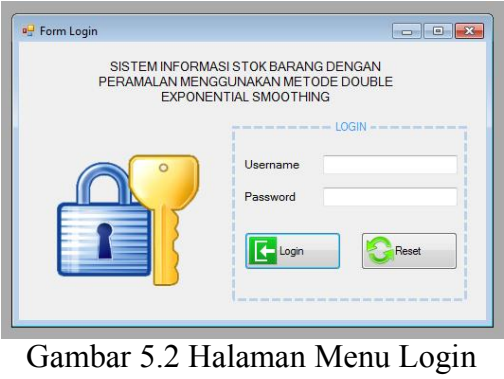

b. Halaman Utama (Petugas Administrasi)

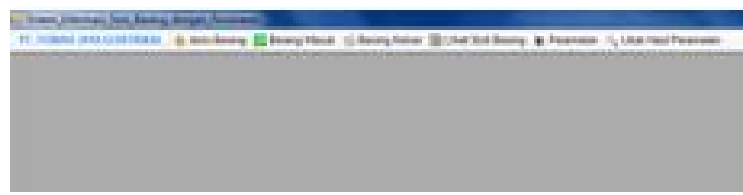

Gambar 5.3 Halaman Utama (Petugas Administrasi) 
c. Halaman Menu Jenis Barang

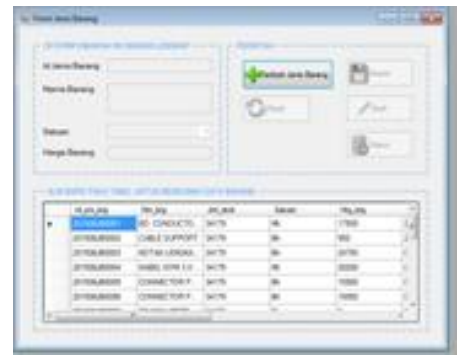

Gambar 5.4 Halaman Menu Jenis Barang

d. Halaman Menu Barang Masuk

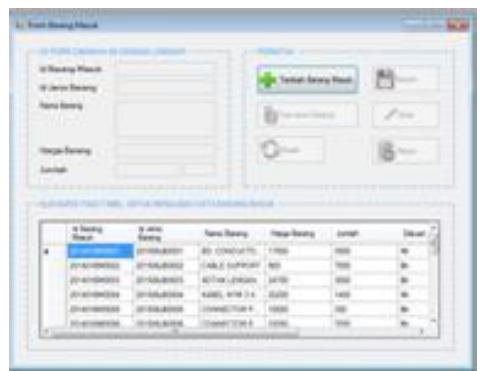

Gambar 5.5 Halaman Menu Jenis Barang

e. Halaman Menu Barang Keluar

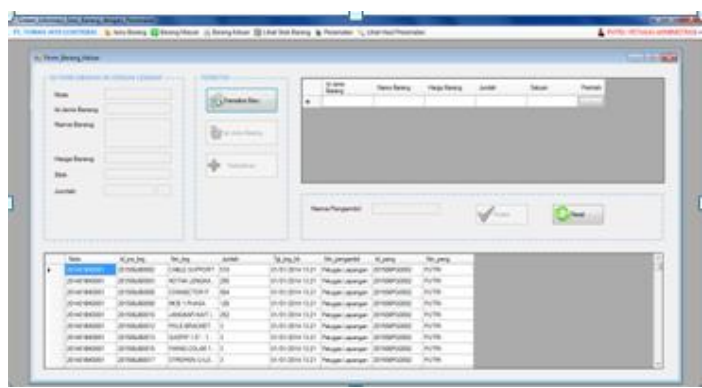

Gambar 5.6 Halaman Menu Jenis Barang

\section{f. Halaman Menu Lihat Stok Barang}

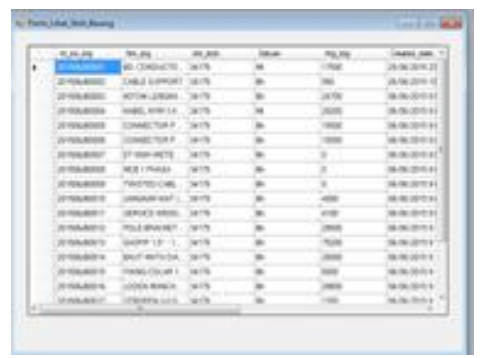

Gambar 5.7 Halaman Menu Lihat Stok Barang

\section{g. Halaman Menu Peramalan}

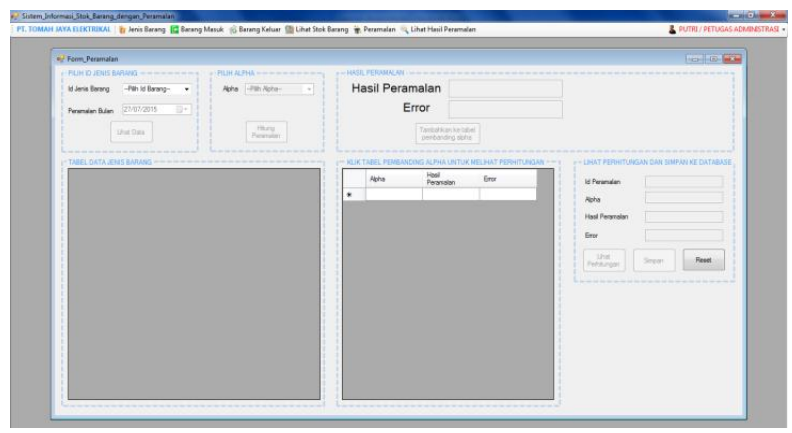

Gambar 5.8 Halaman Menu Peramalan

\section{h. Halaman Menu Lihat Hasil Peramalan}

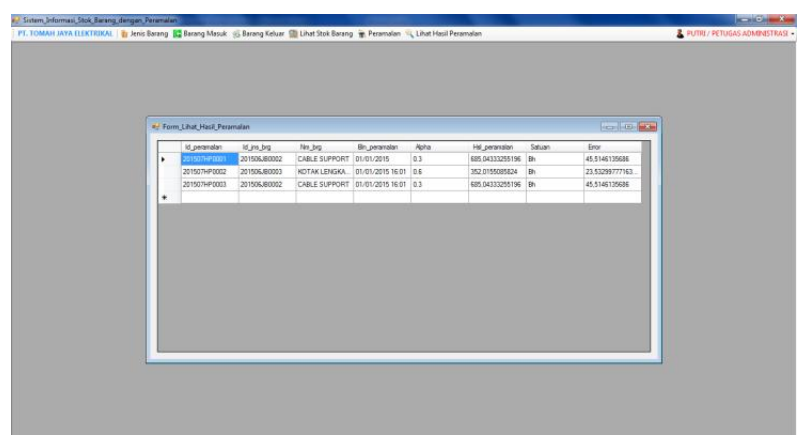

Gambar 5.9 Halaman Lihat Hasil Peramalan

\section{i. Halaman Utama (Admin)}

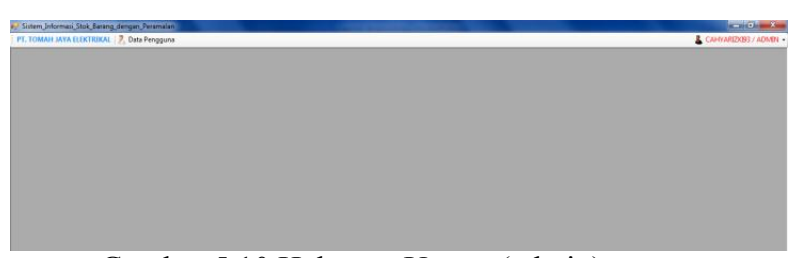

Gambar 5.10 Halaman Utama (admin)

\section{j. Halaman Menu Data Pengguna}

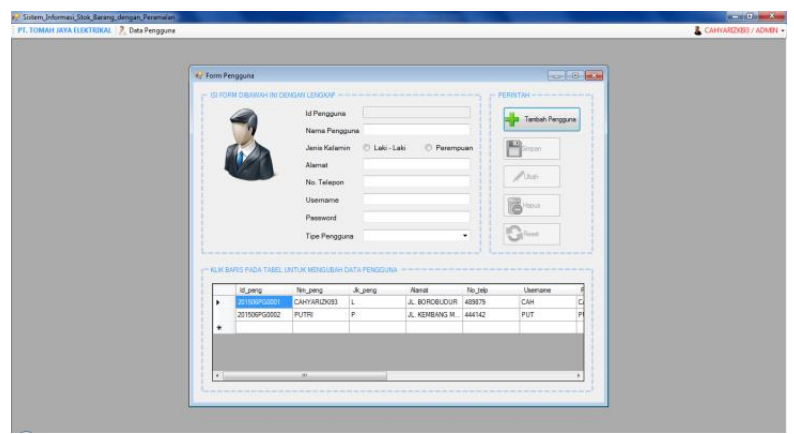

Gambar 5.11 Halaman Data Pengguna 


\section{Pengujian dan Pembahasan}

\subsection{Skenario Uji Coba}

Tabel 6.1 Skenario Uji coba

\begin{tabular}{|l|l|l|l|}
\hline NO & $\begin{array}{l}\text { Case yang } \\
\text { diuji }\end{array}$ & $\begin{array}{l}\text { Point yang } \\
\text { diuji }\end{array}$ & Hasil \\
\hline 1 & Login & $\begin{array}{l}\text { Melakukan } \\
\text { Login }\end{array}$ & Sesuai \\
\hline 2 & $\begin{array}{l}\text { Mengelola } \\
\text { Data Jenis } \\
\text { Barang }\end{array}$ & $\begin{array}{l}\text { Insert, Update, } \\
\text { Delete data } \\
\text { Jenis Barang }\end{array}$ & Sesuai \\
\hline 3 & $\begin{array}{l}\text { Mengelola } \\
\text { Data Barang } \\
\text { Masuk }\end{array}$ & $\begin{array}{l}\text { Insert, Update, } \\
\text { Delete data } \\
\text { Barang Masuk }\end{array}$ & Sesuai \\
\hline 4 & $\begin{array}{l}\text { Mengelola } \\
\text { Data Barang } \\
\text { Keluar }\end{array}$ & $\begin{array}{l}\text { Insert, Update, } \\
\text { Delete data } \\
\text { Barang Keluar }\end{array}$ & Sesuai \\
\hline 5 & $\begin{array}{l}\text { Melihat Stok } \\
\text { Barang }\end{array}$ & $\begin{array}{l}\text { Melihat stok } \\
\text { masing masing } \\
\text { barang }\end{array}$ & Sesuai \\
\hline 6 & $\begin{array}{l}\text { Melakukan } \\
\text { Peramalan }\end{array}$ & $\begin{array}{l}\text { Hitung } \\
\text { peramalan, lihat } \\
\text { hasil } \\
\text { perhitungan, } \\
\text { dan menambah } \\
\text { hasil peramalan. }\end{array}$ & Sesuai \\
\hline 7 & $\begin{array}{l}\text { Melihat Hasil } \\
\text { Peramalan } \\
\text { Delihat hasil } \\
\text { peramalan dari } \\
\text { barang. }\end{array}$ & Sesuai \\
\hline Penguna & $\begin{array}{l}\text { Insert, Update, } \\
\text { Pelete data } \\
\text { Pengguna }\end{array}$ & Sesuai \\
\hline
\end{tabular}

\subsection{Pengujian Metode}

Dari hasil perhitungan yang telah dilakukan, dapat dilihat bahwa nilai MAD berbeda dalam setiap alpha $(\alpha)$ yang digunakan. Untuk lebih jelasnya dapat dilihat pada tabel 6.3 dibawah ini

Tabel 6.3 Tabel Pengujian Alpha

\begin{tabular}{|c|c|c|c|}
\hline \multirow[b]{2}{*}{$\begin{array}{l}\text { Alph } \\
\mathrm{a}(\alpha)\end{array}$} & \multicolumn{3}{|c|}{ MAD Pada Jenis Barang : } \\
\hline & $\begin{array}{l}\text { BD. } \\
\text { CONDUCT } \\
\text { OR } 3 \text { X50 + } \\
\text { 1X35 MM2 } \\
\text { (@50 CM) } \\
\text { Data } 1\end{array}$ & $\begin{array}{l}\text { KABEL } \\
\text { NYM } 3 \\
\text { X } 4 \\
\text { MM2 } \\
\text { Data } 4\end{array}$ & $\begin{array}{l}\text { CONNECT } \\
\text { OR PRESS } \\
\text { AL/AL } \\
\text { TYPE CPTO } \\
\text { 70/70-25/35 } \\
\text { MM2 \& } \\
\text { Data 5 }\end{array}$ \\
\hline 0,1 & 30,44 & 12,06 & 10,4 \\
\hline 0,2 & 22,493 & 8,938 & 7,0268 \\
\hline 0,3 & 20,6799 & 8,14228 & 5,89405 \\
\hline 0,4 & 20,74307 & 8,147471 & 5,355908 \\
\hline 0,5 & 21,126154 & $\begin{array}{l}8,326882 \\
1\end{array}$ & 5,4209872 \\
\hline 0,6 & 23,533 & 9,293103 & 5,72243 \\
\hline 0,7 & 25,6743 & 10,1517 & 6,02952 \\
\hline 0,8 & 27,4445 & 10,8594 & 6,52348 \\
\hline 0,9 & 29,0035 & 11,4068 & 7,024 \\
\hline
\end{tabular}

Hasil MAD terkecil dari BD. CONDUCTOR 3 X50+1X35 MM2 (@50 CM) didapatkan dengan menggunakan alpha $(\alpha)$ 0,3 yaitu dengan nilai MAD sebesar 20,6799. Untuk KABEL NYM 3 X 4 MM2 juga sama didapatkan dengan alpha $(\alpha)$ 0,3 yaitu dengan nilai MAD sebesar 8,14228 , sedangkan CONNECTOR PRESS AL/AL TYPE CPTO 70/7025/35 MM2 \& didapatkan dengan alpha $(\alpha) 0,4$ yaitu dengan nilai MAD sebesar 5,355908. Sehingga nantinya alpha $(\alpha)$ dengan MAD terkecil akan direkomendasikan untuk meminimalkan nilai kesalahan / error pada perhitungan peramalan

\subsection{Pembahasan Metode Double Exponential Smoothing}

Tabel 6.3 Data Barang Keluar

\begin{tabular}{|l|l|}
\hline Bulan & $\begin{array}{l}\text { BD. CONDUCTOR 3 X50 + 1X35 } \\
\text { MM2 (@50 CM) }\end{array}$ \\
\hline Jan-14 & 255 \\
\hline Feb-14 & 210 \\
\hline Mar-14 & 262 \\
\hline Apr-14 & 295 \\
\hline Mei-14 & 297 \\
\hline Jun-14 & 271 \\
\hline Jul-14 & 301 \\
\hline Agust-14 & 293 \\
\hline Sep-14 & 311 \\
\hline Okt-14 & 315 \\
\hline Nop-14 & 325 \\
\hline Des-14 & 342 \\
\hline
\end{tabular}

Data dari jenis barang tersebut sebanyak 12 periode. Maka akan meramalkan Periode ke-13.

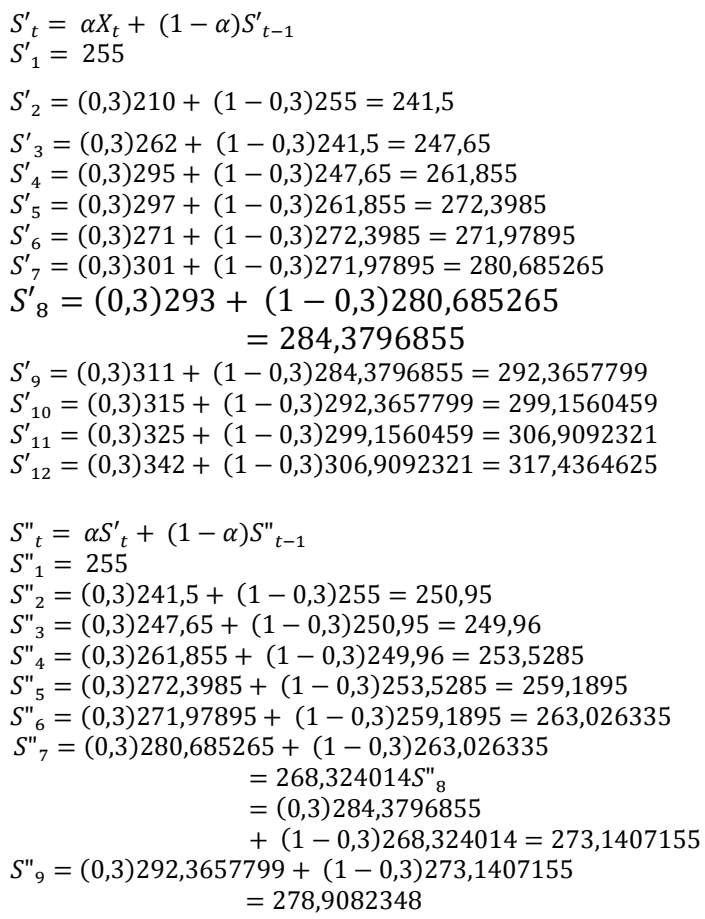

$S_{1}^{\prime}=255$

$S_{2}^{\prime}=(0,3) 210+(1-0,3) 255=241,5$

$S^{\prime}{ }_{3}=(0,3) 262+(1-0,3) 241,5=247,65$

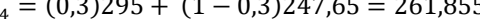

$S^{\prime}{ }_{6}=(0,3) 271+(1-0,3) 272,3985=271,97895$

$S^{\prime}{ }_{7}=(0,3) 301+(1-0,3) 271,97895=280,685265$

$=284,3796855$

$S^{\prime}{ }_{9}=(0,3) 311+(1-0,3) 284,3796855=292,3657799$

$S^{\prime}{ }_{10}=(0,3) 315+(1-0,3) 292,3657799=299,1560459$

$S^{\prime}{ }_{11}=(0,3) 325+(1-0,3) 299,1560459=306,9092321$

$S^{\prime \prime}{ }_{t}=\alpha S_{t}^{\prime}+(1-\alpha) S^{\prime \prime}{ }_{t-1}$

$S^{\prime \prime}{ }_{1}=255$

$S^{\prime \prime}{ }_{2}=(0,3) 241,5+(1-0,3) 255=250,95$

$S^{\prime \prime}{ }_{3}=(0,3) 247,65+(1-0,3) 250,95=249,96$

$S^{\prime \prime}{ }_{4}=(0,3) 261,855+(1-0,3) 249,96=253,5285$

$S^{\prime \prime}{ }_{5}=(0,3) 272,3985+(1-0,3) 253,5285=259,1895$

$S^{\prime \prime}{ }_{6}=(0,3) 271,97895+(1-0,3) 259,1895=263,026335$

$S^{\prime \prime}{ }_{7}=(0,3) 280,685265+(1-0,3) 263,026335$

$=(0,3) 284,3796855$

$+(1-0,3) 268,324014=273,1407155$

$=278,9082348$ 


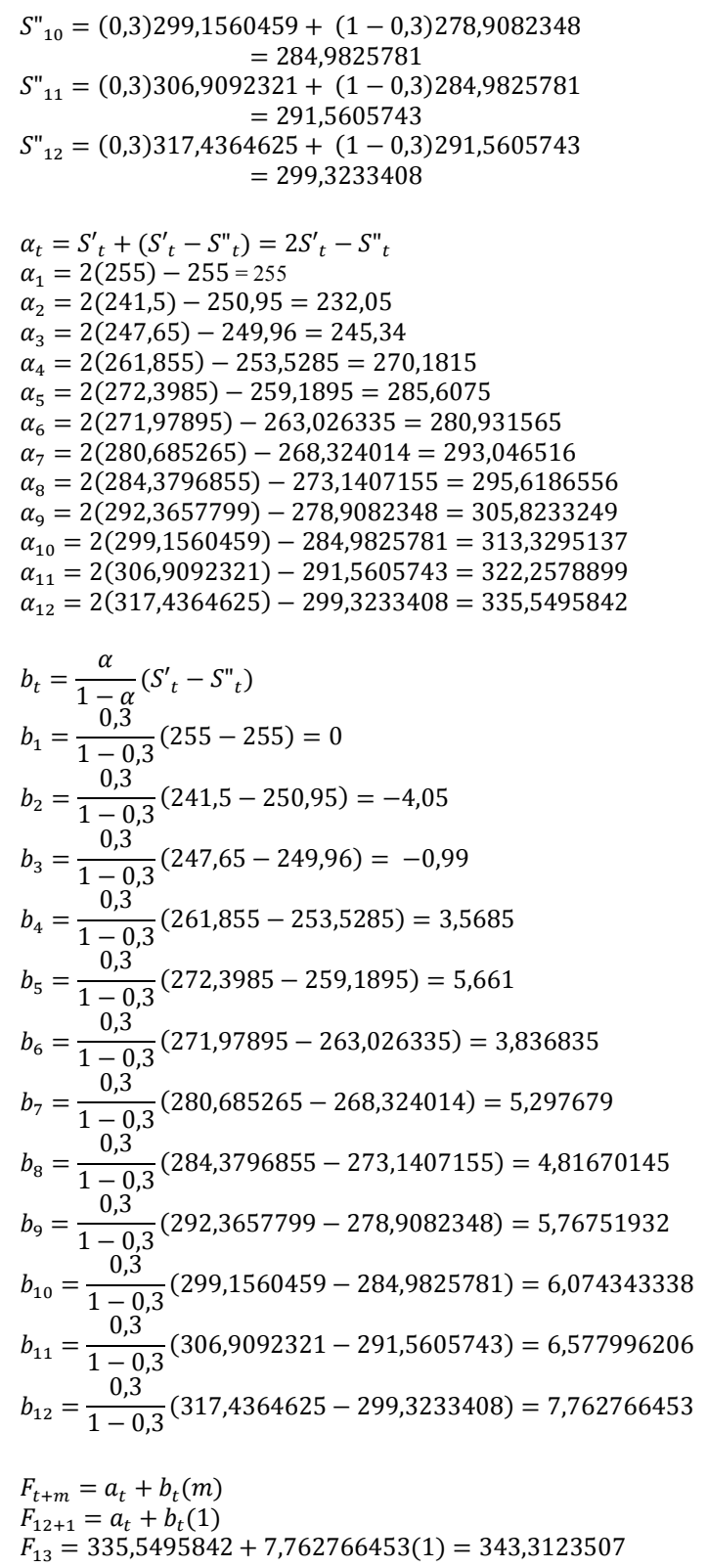

Hasil peramalan untuk periode ke-13 adalah 343,3123507 .

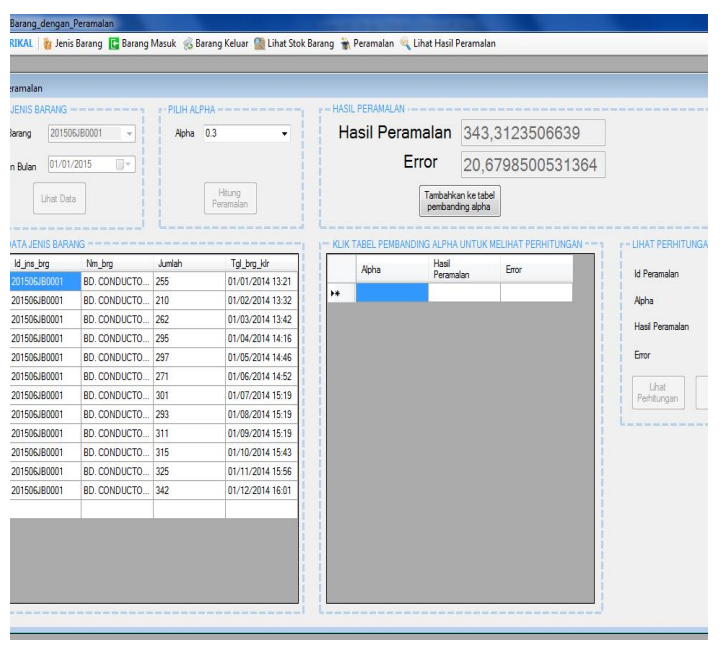

Gambar 6.3 Pembahasan Metode Double Exponential Smoothing

\subsection{Pembahasan Metode Mean Absolute Deviation (MAD)}

Metode ini diaplikasikan untuk mendapatkan rata - rata nilai kesalahan dengan cara menjumlahkan seluruh nilai kesalahan yang diabsolutkan, kemudian dibagi dengan jumlah data.

$$
\begin{aligned}
& M A D=\frac{\sum\left|e_{t}\right|}{\mathrm{n}} \\
& M A D \\
& =\frac{\sum\left|e_{1}+e_{2}+e_{3}+e_{4}+e_{5}+e_{6}+e_{7}+e_{8}+e_{9}+e_{10}+e_{11}+e_{12}\right|}{\mathrm{n}} \\
& M A D \\
& =\frac{\sum \mid \begin{array}{c}
45+34+50,65+23,25+20,2685+16,2316+5,344195+ \\
10,56464+3,409156+5,596143+13,16411
\end{array}}{11} \\
& M A D=\frac{227,4784}{11} \\
& M A D=20,67985
\end{aligned}
$$

Dari perhitungan diatas, didapatkan nilai MAD sebesar 20,67985. Hasil perhitungan manual tersebut diatas sesuai dengan hasil perhitungan MAD pada system.

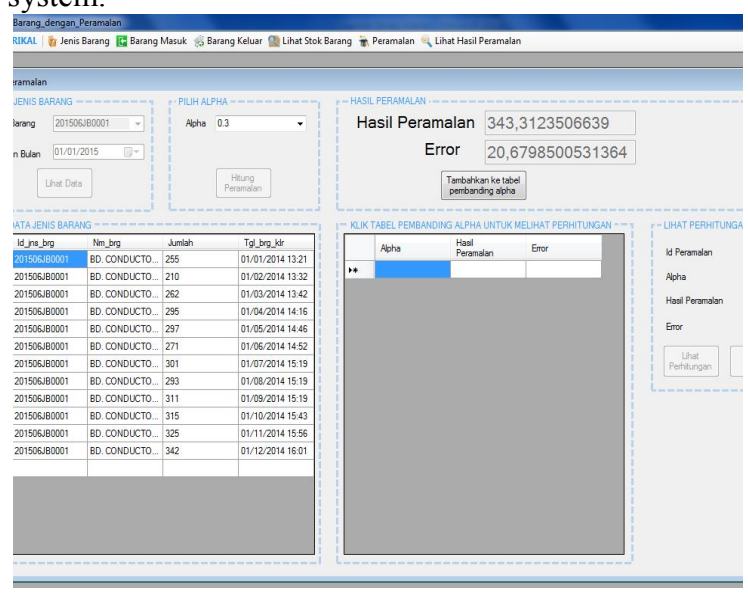

Gambar 6.4 Pembahasan Metode Mean Absolute Error 
7 Kesimpulan

a. Sistem peramalan ini dapat membantu memprediksi kebutuhan stok barang untuk satu bulan kedepan / satu periode kedepan agar stok barang optimal.

b. Nilai alpha $(\alpha)$ yang ditentukan berpengaruh terhadap kesalahan / error dari peramalan.

c. Setelah dibandingkan antara perhitungan manual dengan perhitungan secara sistem, metode Double Exponential Smoothing telah berhasil diterapkan pada sistem ini.

d. Pada peramalan menggunakan metode Double Exponential Smoothing yang telah dilakukan pada 3 sampel data MAD terkecil dari BD. CONDUCTOR 3 X50 + 1X35 MM2 (@50 CM) didapatkan dengan menggunakan alpha $(\alpha)$ 0,3 yaitu dengan nilai MAD sebesar 20,6799. Untuk KABEL NYM 3 X 4 MM2 juga sama didapatkan dengan alpha $(\alpha) 0,3$ yaitu dengan nilai MAD sebesar 8,14228, sedangkan CONNECTOR PRESS AL/AL TYPE CPTO 70/70-25/35 MM2 $\&$ didapatkan dengan alpha $(\alpha) 0,4$ yaitu dengan nilai MAD sebesar 5,355908. Sehingga untuk perhitungan peramalan selanjutnya dapat menggunakan alpha $(\alpha)$ tersebut diatas untuk meminimalkan kesalahan / error pada perhitungan peramalan.

\section{Daftar Pustaka :}

Alda ., et all. "penerapan metode exponential smoothing untuk Peramalan penggunaan waktu telepon di PT.TELKOMSEL DIVRE3 SURABAYA”. SISFO - Jurnal Sistem Informasi Makridakis, S, dkk. (1999). Metode dan Aplikasi Peramalan. Jilid 1. Edisi kedua. Binarupa Aksara, Jakarta.

Nurdina Awwaliyyah, Mahmudah. 2014 "Penerapan Metode Double Exponential Smoothing Dalam Meramalkan Jumlah Penderita Kusta Di Kabupaten Pasuruan Tahun 2014”. Jurnal Universitas Airlangga

Pangestu , 2002., Forecasting, Konsep dan Aplikasi, BPFE-YOGYAKARTA, Yogyakarta

Rachmayati, Pia. "Sistem Informasi Perencanaan dan Pengendalian Persediaan Bahan Makanan pada Instalasi Gizi RSUD Kota Bandung”. Jurnal Ilmiah Komputer dan Informatika (KOMPUTA)

Radiant Victor Imbar, Yon Andreas. 2010. "Sistem Informasi Toko Listrik Aryono King dengan Peramalan Stok Barang menggunakan Metode Double Exponential Smoothing”. Jurnal Informatika, Vol.6, No.1, 65-82

Tommy ., et all. "Sistem Pendukung Keputusan dengan metode Exponential Smoothing untuk meramalkan hasil penjualan pada studi kasus home industri kue Kayu Manis". Jurnal Universitas Brawijaya Malang

Zayn Firdausi. "Implementasi Peramalan Penjualan Menggunakan Metode Exponential Smoothing (Studi Kasus : Penjualan Produk Aksesoris Olahraga di Toko Trend Soccer)". Jurnal Universitas Trunojoyo 